\title{
Characteristics of successful aging of older adults in Nuevo Leon
}

\author{
José M. Ramírez-Aranda**, Paulina A. Barragán-Hernández¹, Raúl F. Gutiérrez-Herrera", \\ Iracema Sierra-Ayala ${ }^{1}$, and Azucena M. Rodríguez-González² \\ ${ }^{1}$ Family Medicine, University Hospital "Dr. José Eleuterio González"; ${ }^{2}$ Medical School. Autonomous University of Nuevo Leon, Monterrey, Nuevo Leon, \\ Mexico
}

\begin{abstract}
Objective: The objective of this study was to know the characteristics of older adults with successful aging (SA) in the state of Nuevo León. Materials and methods: A descriptive, cross-sectional, survey-type study, in a population of 240 adults over 65 in the state of Nuevo León, of both sexes being patients or patient companions', Outpatient Clinic of the University Hospital, and the lower floor of the City Hall of Monterrey and older adults in the EGADE Business School. Results: We found a high percentage of SA in older adults sampled in the state of Nuevo Leon. SA was found in patients without cognitive impairment (odds ratio [OR] 3.5, 95\% confidence interval [CI 95\%] 1.9-6.3), in retirees (OR 2.9, 95\% Cl 95\% 1.5-5.3), in healthy patients or companions (OR 2.1, Cl 95\% 1.0-4.3), male (OR 2.5, Cl 95\% 1.3-4.6), and high schooling interviewees (OR 4.6, Cl 95\% 2.0-10.7). In general, 57.9\% have no cognitive impairment, according to Mini-Mental State Examination. Conclusions: We found $S A$ in $50.9 \%$ of patients and $66.1 \%$ in apparently healthy companions. The absence of cognitive impairment, high school, male sex, and being retired from an institutional system, is associated with SA in adults over 65 years. The prevalence of $S A$ in this sample was higher than that found in other studies.
\end{abstract}

Key words: Successful aging. Active aging. Healthy aging. Elderly. Successful aging index.

\section{Introduction}

The demographic transition in Mexico, which has been called the aging phenomenon, represents a significant challenge for the health sector since this type of population will require specific attention'.

In Nuevo Leon, in 2015, according to the National Institute for Older Persons (INAPAM acronym in Spanish), those 60 years old or more represent $8.9 \%$ of the total population ${ }^{2}$. The population phenomenon has developed due to a reduction in mortality and a decrease in the birth rate ${ }^{3}$.

Aging generally implies a loss of function, higher morbidity, etc. Nevertheless, there can be a successful aging $(\mathrm{SA})$ process. Several terms have been used as a synonym for SA including healthy, active, productive, optimal, or positive aging. However, a more generalized definition focuses on the functioning of everyday life and physical health ${ }^{4}$.

This aging process depends on several genetic, biological, social, and psychological conditions ${ }^{5}$, making it an individual phenomenon. The consensus among authors is that the determinants of SA are potentially multifactorial, although research usually reduces them to lifestyles ${ }^{4}$, physical activity, and the absence of drug addiction ${ }^{6}$ and also the development of good eating habits ${ }^{7}$, occupations $^{8}$, social participation ${ }^{9}$, and social support ${ }^{10}$. Therefore, they have a low probability of getting sick and disabled associated with a disease, a high cognitive and physical functionality, and a commitment to life $3,5,11,12$.

\section{Correspondence:}

*José M. Ramírez-Aranda

E-mail: sersabe2010@gmail.com
Date of reception: 16-03-2019

Date of acceptance: 09-10-2019 DOI: 10.24875/RMU. 19000079
Available online: 09-12-2019
Medicina Universitaria. 2019;21(4):175-179
www.medicinauniversitaria.org www.medicinauniversitaria.org (http://creativecommons.org/licenses/by-nc-nd/4.0/). 
In the same track, some other authors like Ballesteros et al. have identified the predictive factors of aging among individuals are sociodemographic, higher income, better education, regular physical activity (among these, the most important variables were strength and lung capacity), and psychological characteristics related to intelligence, personality, and motivation, among others ${ }^{4}$. Among those, physical activity and social activation were demonstrated as very important factors in the prevention of anxiety and late depression ${ }^{13}$.

The reason for conducting this research is to know the profile of older adults who present SA and has an idea about the prevalence of the phenomenon in our state. This would be the first advancement in knowledge regarding this population to subsequently study the factors associated with SA to correct those factors that prevent it or strengthen those that favor it.

\section{Materials and methods}

This was a cross-sectional, descriptive survey of elderly population of the state of Nuevo Leon. We included adults over 65 years of age of both sexes. They were approached in the Outpatient Clinic of the University Hospital, on the ground floor of the City Hall of Monterrey during a weekend folk festival, and in the EGADE private postgraduate business school of the Tec de Monterey. We excluded those who did not want to participate and those with evident cognitive impairment (Cl) or with some incapacitating psychiatric illness.

A convenience sample was used in the mentioned study sites as long as individuals met the inclusion criteria. For the estimation of sample size, a formula for epidemiological studies was used, reaching a final sample of 240 participants.

An instrument was designed that consisted of (I) demographic data, age, sex, education, and socioeconomic level measured by the AMAI scale ${ }^{14}$ and (II) the SA index (SAI) for measuring SA. The SAI was designed by Theodore D. Cosco ${ }^{15}$, and it consists of 20 items that use operational definitions. This tool was used because it incorporates both objective physiological measures and subjective psychosocial measures of SA. Those components were based on the Katz Index, the Lawton and Brody scale ${ }^{16,17}$, and the Folstein Mini-Mental State (Mini-Mental State Examination $[\mathrm{MMSE}])^{18}$. Besides, some items related to the older person's perception of their future, their health and loneliness, were included in the study. The SAI was created using a protocol similar to the fragility index, based on the number of possible answers. Values were assigned, fractional, for example, for a Likert-type response of four answers. The response corresponding to the highest level of function would receive 100 , the next 67,33 , and finally 0 for the lowest possible level. For continuous variables, for example, MMSE, previous cutoff points: $\geq 26,25-22,21-18$, and 17-0 with fractional values were used, according to the protocol used in Searle et al. This scale has a predictive validity in the English population, where values of the area under the curve and the receiver operating characteristics curve fluctuated between 0.65 and $0.86^{15}$.

After obtaining prior informed consent, the participant was invited to answer the instrument in a private area, where the questionnaire was completed in approximately $10 \mathrm{~min}$. The instrument was applied by two of the authors (PABH, AMRG), after training. No economic stimulus was offered for participation in the survey.

\section{Statistical analysis}

The data were captured with SPSS version 20 for Windows and analyzed with descriptive statistics for percentages and frequencies of categorical variables, and means and standard deviations for continuous variables.

According to the Kolmogorov-Smirnov test, the distribution of the data was not normal, so the score obtained on the SAI was established as successful and unsuccessful aging according to the median. The SA variable was cross-referenced with the demographic and socioeconomic data using Chi-square with $p<0.05$.

The level of education was recorded as low, those from the $2^{\text {nd }}$ year of junior high school and lower (21 points and less for individuals with $\mathrm{Cl}$, and 18 and less for illiterate individuals) and high, those from the $3^{\text {rd }}$ year of secondary school and higher, according to the years of the study ${ }^{3,19}$.

\section{Ethical considerations}

The protocol was approved by the Ethics and Research Committees of the University Hospital.

\section{Results}

A total of 240 older adults were studied with a general prevalence of SA of $62.5 \%$ (Fig. 1). Of these, 141 were female $(58.8 \%)$ with a mean age of $71.7 \pm 5.7$. Males were $99(41.2 \%)$ with a mean age of $73.8 \pm 6.4$. Education prevailed until complete primary school (68.7\%); in marital status, $56.3 \%$ were married, and in religion, 


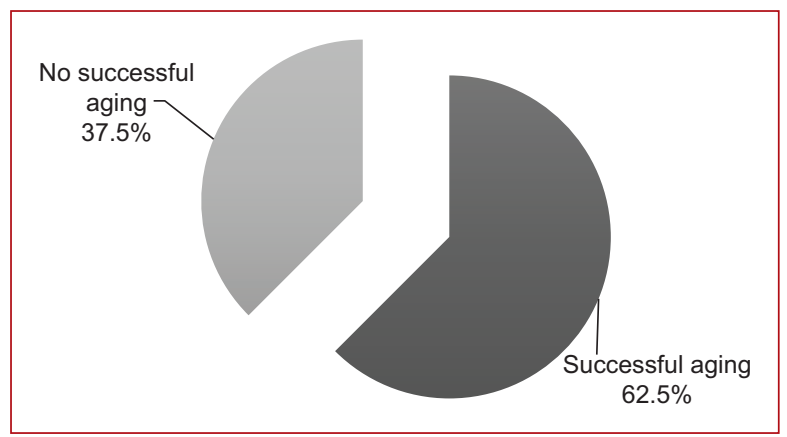

Figure 1. Percentage of successful aging.

$80.4 \%$ were Catholics. The majority was not receiving a retirement pension (Table 1). Of the group, $75 \%$ suffered some disease, especially chronic degenerative diseases alone or in a multimorbid pattern (Table 2).

Of the study population, $50.9 \%$ of the patients and $66.1 \%$ of the respondents who correspond to non-patients or companions showed scores corresponding to $S A(p<0.05)$. We found an association of SA with male sex patients, high level of education, retired, healthy participants, as well as those without $\mathrm{Cl}$ (Table 3).

\section{Discussion}

In this study, the prevalence of SA was high considering the types of populations studied: we included patients from an Outpatient Clinic of Family Medicine of a University Hospital, the companions of patients (apparently healthy), with a higher prevalence of SA in the latter population but above all groups of older adults belonging to a very high socioeconomic area (municipality of San Pedro Garza Garcia).

In general, the results of activities of daily life by older adults could be performed without difficulty with an average percentage higher than $80 \%$; therefore, the degree of independence was quite good given that the participants moved to place inside and outside of the hospital, and even participated in activities such as dancing (City Hall of Monterrey).

This prevalence of SA was higher than that reported by Ballesteros (15.5-41.4\%), in Madrid, Spain, using a similarly diverse subpopulation; i.e., rural population, university students, and volunteers, with a mean age of 66 years, and notably, those who were independent to carry out daily life activities which could determine a higher SAI score 4 .

On the other hand, Carrasco et al. reported a prevalence of $40.4 \%$ in patients from a general hospital in Colima, Mexico ${ }^{20}$; this was lower than that found in this
Table 1. Sociodemographic data of older adults

\begin{tabular}{|c|c|c|}
\hline Variable & Frequency & Percentage \\
\hline $\begin{array}{l}\text { Gender } \\
\text { Male } \\
\text { Female }\end{array}$ & $\begin{array}{c}99 \\
141\end{array}$ & $\begin{array}{l}41.2 \\
58.8\end{array}$ \\
\hline $\begin{array}{l}\text { Education } \\
\text { Illiterate } \\
\text { Incomplete elementary } \\
\text { Complete elementary } \\
\text { Incomplete junior high } \\
\text { Complete junior high } \\
\text { High school } \\
\text { Bachelor's degree } \\
\text { Postgraduate }\end{array}$ & $\begin{array}{c}21 \\
96 \\
48 \\
15 \\
22 \\
13 \\
19 \\
9\end{array}$ & $\begin{array}{c}8.7 \\
40.0 \\
20.0 \\
6.3 \\
9.1 \\
5.4 \\
6.7 \\
3.8\end{array}$ \\
\hline $\begin{array}{l}\text { Marital status } \\
\text { Married } \\
\text { Single } \\
\text { Divorced/separated } \\
\text { Widowed }\end{array}$ & $\begin{array}{l}135 \\
19 \\
24 \\
62\end{array}$ & $\begin{array}{c}56.3 \\
7.9 \\
10.0 \\
25.8\end{array}$ \\
\hline $\begin{array}{l}\text { Religion } \\
\text { Catholic } \\
\text { Christian } \\
\text { Jehovah's witness } \\
\text { None } \\
\text { Other }\end{array}$ & $\begin{array}{c}193 \\
19 \\
6 \\
12 \\
10\end{array}$ & $\begin{array}{l}80.4 \\
7.9 \\
2.5 \\
5.0 \\
4.2\end{array}$ \\
\hline $\begin{array}{l}\text { Occupation } \\
\text { Housewife } \\
\text { Small business } \\
\text { None } \\
\text { Other }\end{array}$ & $\begin{array}{l}82 \\
19 \\
71 \\
68\end{array}$ & $\begin{array}{c}34.2 \\
7.9 \\
29.6 \\
28.3\end{array}$ \\
\hline $\begin{array}{l}\text { Remunerated occupation } \\
\text { Yes } \\
\text { No }\end{array}$ & $\begin{array}{l}61 \\
71\end{array}$ & $\begin{array}{l}28.8 \\
71.2\end{array}$ \\
\hline $\begin{array}{l}\text { Retired } \\
\text { Yes } \\
\text { No }\end{array}$ & $\begin{array}{c}98 \\
142\end{array}$ & $\begin{array}{l}40.8 \\
59.2\end{array}$ \\
\hline
\end{tabular}

study. This could be due to the socioeconomic level of the population surveyed in Nuevo Leon, one of the industrial states of the country, obviously with a higher living standard than Colima state.

In general, the sample in this study is a population with a low level of education (75\%); they could be non-retirees $(59.2 \%)$. However, the sample study included more retired persons than in the general population given that in Nuevo Leon; $9.8 \%$ of no economically active population are retired, and in general, a little $<1 / 2$ were not economically active population ${ }^{21}$. SA is more associated with retirees than non-retirees; this could explain the higher prevalence of SA than in other studies ${ }^{4}$.

Other considerations should be born in mind regarding the comparison of the prevalence of SA, such as there is not a single, conventional scale to measure SA. 
Table 2. Medical and institutional data of older adults

\begin{tabular}{|l|c|c|}
\hline Variable & Frequency & Percentage \\
\hline Healthy & 60 & 25.0 \\
\hline III & 180 & 75.0 \\
\hline Type of disease & & \\
HT & 47 & 19.6 \\
DM2 & 32 & 13.3 \\
HT, DM2 & 28 & 11.7 \\
Three or more & 15 & 6.3 \\
diseases (including DM & & \\
and HT) & 118 & 49.1 \\
\hline Other & & \\
\hline Medical service & & 88.3 \\
Institutional & 212 & 5.8 \\
Private & 14 & 5.8 \\
\hline None & 14 & \\
\hline Institutional service & & 40.0 \\
IMSS & 96 & 2.9 \\
ISSSTE & 7 & 15.7 \\
\hline SSA/SP & 100 & \\
\hline Other & 37 & \\
\hline
\end{tabular}

Table 3. Variables associated with successful aging

\begin{tabular}{|l|c|c|}
\hline Variable & OR & $95 \%$ CI \\
\hline Without cognitive impairment & 3.5 & $1.9-6.3$ \\
\hline Retired & 2.9 & $1.5-5.3$ \\
\hline Healthy or accompanying & 2.1 & $1.0-4.3$ \\
\hline Men & 2.5 & $1.3-4.6$ \\
\hline High education level & 4.6 & $2.0-10.7$ \\
\hline
\end{tabular}

OR: odds ratio.

Furthermore, it varies according to the elements that are part of the instruments, for example, Carrasco et al. ${ }^{20}$ used the Barthel index $\geq 90$ and the Pfeiffer test with two or more errors; in this study, we used Cosco's SAI ${ }^{15}$.

On the other hand, it has been shown that the educational level has an impact on $\mathrm{SA}^{3}$. This coincides with our research that significantly showed more SA in people with high education compared to those with low education.

In addition to the aforementioned factors of high income and education, there are other predictive factors associated with the SAI${ }^{4}$, which are not all considered in the current SAI scale. For instance, Ryff's theory on SA includes six criteria such as self-acceptance, personal growth, autonomy, positive relationships with others, control over their environment, and the meaning of life, which do not occur simultaneously in the stages of life $^{22}$. On the other hand, Rowe defines SA as a low probability of illness or of acquiring a disability, a high physical and cognitive capacity, and high social participation ${ }^{4}$.

Few studies have associated cognitive impairment with SA. In this study, it was found that an MMSE score higher than $24,74.8 \%$ would correspond to people with $\mathrm{SA}$. This is higher than that found by Ballesteros, who reported a prevalence of SA of $46 \%$ but with an MMSE cutoff point of 29.

A higher cognitive level has been identified in people with SA compared to those who do not have this ${ }^{5,23}$. That is, the absence of $\mathrm{Cl}$ was associated with more $\mathrm{SA}$, which is not surprising since a proper cognitive function is related to the quality of life ${ }^{24}$, and in contrast, a cognitive deficit with greater fragility (odds ratio 3.2; Cl: 2.0-5.1; $p<0.0001)^{25}$.

\section{Limitations}

The most significant limitation of the study was the sampling method, which was not probabilistic and did not ensure the probability of selecting an absent or poorly accessible population. However, it was attempted to address diverse populations in a socioeconomic stratum, educational level, and different levels of independence and health.

Another limitation is the wide variety of instruments for measuring SA. In this case, Cosco's SAI does not consider all the variables mentioned by other authors as components of the SA construct or active aging.

\section{Conclusions}

A high prevalence of SA was found in the study population, compared with other studies, which could be explained by the kind of studied population.

SA in adults over 65 years is associated with the absence of cognitive impairment, a high education level, male sex, and being pensioned from an institutional system.

\section{Conflicts of interest}

The authors declare that they have no conflicts of interest related to this research.

\section{Ethical disclosures}

Protection of human and animal subjects. The authors declare that no experiments were performed on humans or animals for this study. 
Confidentiality of data. The authors declare that they have followed the protocols of their work center on the publication of patient data.

Right to privacy and informed consent. The authors have obtained the written informed consent of the patients or subjects mentioned in the article. The corresponding author is in possession of this document.

\section{References}

1. Gutiérrez JP, Rivera-Dommarco J, Shamah-Levy T, Villalpando-Hernández S, Franco A, Cuevas-Nasu L, et al. Encuesta Nacional de Salud y Nutrición 2012. Resultados Nacionales. Cuernavaca, México: Instituto Nacional de Salud Pública; 2012.

2. Instituto Nacional de las Personas Adultas Mayores. Perfil Demográfico, Epidemiológico y Social de la Población Adulta Mayor en el País, una Propuesta de Política Pública. México: INAPAM; 2010. Available from http://www.inapam.gob.mx/work/models/INAPAM/Resource/918/1/images/ADULTOS\%20MAYORES\%20POR\%20ESTADO\%20CD1.pdf. [Last accessed on 2016 Jun 29].

3. Fernández-Ballesteros $\mathrm{R}$, Zamarrón-Cassinello $M D$, Díez-Nicolás $J$, De Juan-Espinosa M, Montero P, López-Bravo MD, et al. Estudio Longitudinal sobre Envejecimiento Activo (ELEA). Madrid, IMSERSO; 2006. Available from: http://www.imsersomayores.csic.es/documentos/documentos/ imserso-estudiosidi-38.pdf.

4. Fernández-Ballesteros R, Zamarrón MD, López MD, Molina MA, Díez J, Montero $\mathrm{P}$, et al. Successful ageing: criteria and predictors. Psychol Spain. 2011:15:94-101.

5. Rowe JW, Kahn RL. Successful aging. Gerontologist. 1997;37:433-40.

6. Lafortune L, Martin S, Kelly S, Kuhn I, Remes O, Cowan A, et al. Behavioural risk factors in mid-life associated with successful ageing, disability, dementia and frailty in later life: a rapid systematic review. PLoS One. 2016;11:e0144405.

7. Mendoza-Ruvalcaba NM, Arias-Merido ED. I am active: effects of a program to promote active aging. Clin Interv Aging. 2015;10:829-37.

8. Aguilar-Parra JM, Álvarez-Hernández J, Fernández-Campoy JM, Salguero-García D, Pérez-Gallardo ER. Investigación sobre envejecimiento activo y ocupación como fuente de salud y calidad de vida. Int J Dev Educ Psychol. 2013;2:147-54.

9. Gallardo L, Conde-Llanes D, Córdova-Jorquera I. Asociación entre EE y participación social en personas mayores chilenas. Gerokomos. 2016;27: 104-8.
10. Flores $A E$, Decenas $K$, Avalos ML, Colunga C, Vega MG, Meza IJ. Apoyo social percibido y envejecimiento activo en hombres y mujeres de una comunidad rural. REPI. 2016;19:1316-32.

11. Baltes M, Carstensen L. The process of successful ageing. Ageing Soc. 1996;16:397-422.

12. Williams RH, Wirths CG. Lives Throught the Years: Styles of Life and Successful Aging. New York: Routledge; 1966. p. 1175.

13. Jiménez DE, Reynolds CF, Alegría M, Harvey P, Bartels SJ. Los hispanos felices mayores son activos (HOLA) promoción de la salud y el estudio de prevención: el protocolo de estudio de un piloto controlado aleatorizado. Trials. 2015;16:579.

14. Asociación Mexicana de Agencias de Investigación de Mercado y Opinión Pública. Cuestionario Para la Aplicación de la Regla Amai 2018 y tabla de Clasificación. México: AMAl; 1992. Available from: http://www. nse.amai.org/cuestionarios. [Last accessed on 2019 Jan 21].

15. Cosco TD, Stephan BC, Brayne C. Validation of an a priori, index model of successful aging in a population-based cohort study: the successful aging index. Int Psychogeriatr. 2015;27:1971-7.

16. Lawton MP, Brody EM. Assessment of older people: self-maintaining and instrumental activities of daily living. Gerontologist. 1969;9:179-86.

17. Katz S. Assessing self-maintenance: activities of daily living, mobility, and instrumental activities of daily living. J Am Geriatr Soc. 1983;31: 721-7.

18. Kabátová O, Puteková S, Martinková J, Súkenníková M. Analysis of psychometric features of the mini-mental state examination and the montreal cognitive assessment methods. Clin Soc Work Health Interv. 2016; 7:62-9.

19. Escribano-Aparicio MV, Pérez-Dively M, García-García FJ, Pérez-Martín A, Romero L, Ferrer G, et al. Validación del MMSE de folstein en una población española de bajo nivel educativo. Rev Esp Geriatr Gerontol. 1999;34:311-68.

20. Carrasco-Peña KB, Faráis-Moreno K, Trujillo-Hernández B. Frecuencia de EE y fragilidad. Factores de riesgo asociados. Rev Esp Geriatr Gerontol. 2018:53:23-5.

21. Instituto Nacional de Estadística y Geografía. Panorama Sociodemográfico de México. México: INEGl; 2015. Available from: http://www.seieg. iplaneg.net/seieg/doc/Panorama_Sociodemografico_2015_1452886126. pdf. [Last accessed on 2019 Jan 21].

22. Ryff $C D$. In the eye of the beholder: views of psychological well-being among middle-aged and older adults. Psychol Aging. 1989;4:195-201.

23. Rowe JW, Kahn RL. Human aging: usual and successful. Science. $1987 ; 237: 143-9$

24. Elena NG, Miriam SG, Silvia AF. Funcionamiento cognitivo y calidad de vida en ancianos con y sin EE. Eur J Health Res. 2017;3:75-89.

25. Karla CP, Katia FM, Benjamín TH. Frecuencia de envejecimiento exitoso y fragilidad. Factores de riesgo asociados. Rev Esp Geriatr Gerontol. 2018;53:23-5. 